\title{
O BIOPODER NA CONTEMPORANEIDADE E A ALTERNATIVA BUDISTA
}

\author{
Gabriela Bastos Soares
}

Resumo: Esse trabalho analisa os recursos inseridos nos domínios da moralidade e da política que vêm contribuir para a construção de estilos de vida diversos na contemporaneidade. No universo de possibilidades, as práticas que recorrem à transcendência oferecem meios para a construção de uma visão de mundo que tem implicaçôes significativas para o sujeito. Nesse sentido, o mundo atual concede ao sagrado um novo impulso e revaloriza a religião como fonte de significado para a experiência humana. A perspectiva desenvolvida destaca o exercício do budismo hoje no Ocidente, pela afinidade eletiva existente entre suas características e as regras da culturasomática e pela plausibilidade dessas equivalências serem adequadas para a resolução de alguns impasses para o sujeito na atualidade. O budismo é visto como um caminho alternativo para a valorização dos referentes morais e políticos implicados na constituição das subjetividades.

Palavras-chave: Corpo - Subjetividades - Religião - Budismo

Abstract: The present work analyses the resources within morality and politics which contribute to the construction of diverse lifestyles in the contemporary world. Within the range of possibilities available practices resortingto transcendence offer a means for the construction of a world view which has significant implications for the subject. In that sense, today's world offers the sacred a new impulse and rehabilitates religion as a source of meaning for human existence. The perspective developed here highlights the practice of Buddhism in the West today due to the elective affinity found between its characteristics and the rules of the somatic culture, as well as to the plausibility that these equivalences are adequate for the resolution of some situations of impasse which the subject in the present world. Buddhism is seen as an alternative path in re-stressing the value of the moral and political reference points implicated in the constitution of subjectivities.

Keywords: Body - Subjectivities - Religion - Buddhism

Doutora em Saúde Coletiva (UERJ). Professora do Centro Universitário Metodista Bennett (gbastos.ntg@terra.com.br). 


\section{INTRODUÇÃO}

O percurso trilhado pela presente pesquisa partiu da tentativa de analisar certas crenças culturais vigentes no mundo atual. A análise centrou-se na pertinência de determinadas possibilidades no domínio da moral e da política quando articuladas aos referentes do corpo e da saúde hoje. $\mathrm{Na}$ modernidade, a valorização do corpo e da biologia serviram como ferramentas para alcançar outros objetivos, como os relacionados ao trabalho ou à família. Hoje se tornaram não apenas meios, mas também os próprios fins. Abordou-se algumas das dificuldades desse modelo. O corpo, concreto ou simbólico, foi visto como passível de ser utilizado como ferramenta para a constituição das subjetividades. Mas seu uso como fim em si mesmo incorre em alguns impasses. Dois argumentos endossam tal afirmação: o corpo como referente é extremamente limitado em termos de alternativas para as práticas de si, pois suas descrições são restritas; e esses referentes demandam do sujeito um processo interminável de construção do significado último da vida, o que se transforma em uma constante busca de bem-estar que, paradoxalmente, acarreta mal-estar. Diante dessa perspectiva, foram investigadas trajetórias possíveis para o sujeito concernentes ao exercício dessa nova modalidade de governo de si. O intento foi fornecer referentes para a construção de vias factuais na formação do sujeito contemporâneo, por meio de um caminho interpretativo alternativo. A hipótese era que o culto excessivo ao corpo, quando articulado ao arsenal das práticas espirituais, pode proporcionar saídas para algumas fontes de mal-estar na atualidade.

É possível dizer que existem hoje alternativas para o indivíduo e para a sociedade em termos da valorização do corpo. $\mathrm{O}$ império do biológico reina, mas não é um soberano absoluto. $\mathrm{O}$ exercício do seu poder é restrito ao domínio do imanente. A questão é que para dotar a vida de sentido último é imprescindível a recorrência a alguma transcendência. Por isso, foram analisadas as técnicas que retiram as asceses da dimensão da imanência corporal e a ligam a objetivos transcendentes. $\mathrm{Na}$ busca por um tipo de transcendência adequada aos valores da sociedade ocidental contemporâ- 
nea, a religião foi vista como uma via plausível para o sujeito. A referência da religião pode engendrar valores como a consideração ao outro, morais que atentam para o aspecto corpóreo mas que não se reduzem a ele, e asceses que tem como objetivo a transcendência. Assim, é possível dizer que paralelo ao império da biotecnologia é factível a recorrência às asceses espirituais, até mesmo porque há uma afinidade eletiva entre determinadas asceses espirituais contemporâneas e as tecnologias corporais e médicas.

O budismo foi utilizado como exemplar dessa alternativa ao biopoder. ${ }^{1}$ A cultura somática e a ideologia budista não são antagonistas, apesar de serem aparentemente conflituosas. Isso não implica dizer que a prática do budismo é a única saída para os impasses do biopoder. Não apenas existem outras formas de transcendência, como o budismo também pode ser praticado com fins diferentes dos que se propõe. Na contemporaneidade, essa é uma alternativa promissora, que contribui para o enriquecimento dos vocabulários que descrevem a subjetividade.

\section{A TRANSCENDÊNCIA}

Para abordarmos o tema da transcendência e do religioso na atualidade é necessário explicitar o sentido que utilizamos na pesquisa. A perspectiva desenvolvida nessa pesquisa opta pela linha que demarca a religião como um fenômeno produzido pelos homens para conhecer o mundo e situar-se nele. Nessa tradição inserem-se pensadores como Durkheim, Weber,

\footnotetext{
${ }^{1} \mathrm{O}$ termo biopoder foi utilizado por Foucault para se referir ao valor que o corpo e a saúde adquiriram na formação das subjetividades a partir da modemidade. $\mathrm{O}$ biopoder deve ser visto como um tipo de poder exerado sobre o corpo e a vida, que tem dois pólos de ação: a anátomo-política, voltada para o indivíduo, e a biopolítica, centrada na população. As duas estratégias utilizavam dispositivos espećficos para a administração dos corpos e a gestão calculista da vida, ambos considerados por Foucaultcomo disciplinares.A disciplinacriou regras para controle e gestão dos indivíduos e da população, elaboradas a partir de conceitos e teorias, por meio da normalização. $\mathrm{Na}$ artiaulação dessas técnicas e sua aplicação, os elementos comuns amplamente utilizados foram o racismo e a sexualidade (Foucault, 1994).
} 
Troeltsch, Luckmann e Berger. Para definirmos de forma precisa o uso que consideramos mais interessante para o nosso objetivo, recorremos às concepçōes de Troeltsch (1996) e Luckmann (1967). A perspectiva de ambos os autores leva à compreensão da religião como além das perspectivas institucionalizadas formalmente. O religioso, para Troeltsch, tinha um sentido amplo, não estava circunscrito nem a enunciados doutrinais nem a instituições reconhecidas. A partir dessas possibilidades, Troeltsch indicou a existência de três tipos de religião: a religião de igreja, a religião de seita e a religião espiritual e mística. Na proposta de Troeltsch a religião mística tinha como marca distintiva a não institucionalização formalizada e a abertura para a criação da própria religiosidade. Luckmann estava interessado em analisar as condições nas quais as estruturas transcendentes, ordenadoras e integradoras de significado objetivavam-se socialmente. A idéia principal é que o sentido do ato religioso não está fora do universo simbólico. Essa seria a raiz do fenômeno religioso. A compreensão da condição antropológica da religião está relacionada ao sentido de universo simbólico. Os universos simbólicos podem ser definidos como sistemas de significado socialmente objetivados, que têm por referência a vida cotidiana e o que é experimentado como transcendente a essa vida.

A forma social do religioso na modernidade é fundamental para melhor entender o significado atual, a partir das rupturas e das continuidades desses modelos. Para Luckmann, a modernidade pluralizou o uso da religião. Apesar de haver a recorrência às religióes tradicionais, já institucionalizadas, também ocorreu uma adaptação a um novo arranjo construído de maneira mais secular. A marca da modernidade foi o que o autor designa como religiāo invisivel. Luckmann relaciona a religião invisível com a atitude consumista do mundo moderno. A religião não desapareceu, mas se tornou invisível socialmente por ficar restrita à esfera privada. Notese que a retirada para a esfera privada da religião na situação contemporânea não quer dizer a ineficiência social das motivaçôes do homem religioso, mas que ele passou a encontrar e construir por si o conjunto de suas motivaçôes religiosas, apoiando-se menos no grupo e nas suas estruturasde plausibilidade.

É possível questionar como é exercida essa articulação pelo sujeito con- 
temporâneo. A idéia aqui desenvolvida é que as características da religião invisível descrita por Luckmann possuem forte identidade com os temas atuais que servem como mediadores da relação indivíduo/sociedade no Ocidente.

Segundo Champion e Hervieu-Léger (1990), no mundo inteiro surge uma espécie de surto de espiritualidade, nem sempre no sentido religioso do termo, mas principalmente como busca de algo mais profundo na vida: uma nova relação das pessoas consigo mesmas, com o universo e com uma transcendência que se manifesta na vida terrena. Os movimentos religiosos voltaram a ser expressivos no mundo contemporâneo, perspectiva praticamente inexistente há 30 anos. Vernette e Moncelon (2001) enumeraram 476 grupos religiosos existentes na atualidade. Para os autores, há um duplo movimento na retomada da religião no Ocidente. De um lado, a diminuição das religiões oficiais sob certos aspectos institucionalizados, de outro, o surgimento cada vez maior de novas religiōes. O movimento de retorno ao religioso tem abertura para a utilização de práticas novas ou renovadas, constituindo grupos e movimentos diversos. As Igrejas e grandes religiōes tradiciona is são marcadas por inovações e afetadas por movimentos de cisão interna. Grupos espirituais novos, voltados para os movimentos gnósticos, esotéricos ou fundados em outras tradições, surgem para protestar contra a ditadura do racionalismo e do materialismo. Magia, feitiçaria, bruxaria, artes adivinhatórias e satanismo são praticados, seja individualmente ou em grupos organizados. Também há os grupos que se apóiam em psicoterapias e, na procura por interioridade e desenvolvimento pessoal, transformam essas práticas em grupos considerados como uma religião-substituta. Por fim, há os grupos sob influência das religiōes orientais, que propõem vias espirituais adaptadas ao Ocidente.

A religiosidade na atualidade forma um quadro confuso de influências diversas. É cada vez mais comum uma busca do sagrado que se manifesta de maneiras variadas. Uma espécie de sincretismo religioso, onde é possível mesmo criar um "deus próp rio". Muitas vezes os in divíduos compõem seu mundo religioso sem adotar em bloco a proposta das instituições. Produzem sua religião com aspectos que procedem de diferentes tradiçôes. Alguns 
vivem a renovação espiritual ou carismática dentro das próprias Igrejas. Outros preferemuma versão mais livre da espiritualidade e buscam um caminho independente das religióes organizadas. Muitos retomam crenças das antigas religiōes orientais ou indígenas, ou apelam para as construçôes atuais.

$\mathrm{Na}$ nova espiritualidade o fator fundamental é a própria subjetividade, baseada na forma de pensar, sentir, viver e agir que se volta para a dimensão sagrada e espiritual de cada pessoa e do universo. O Deus cristão tornou-se mais uma das divindades possíveis no politeísmo atual, guiado pela ética da tolerância e por um mínimo de regras de convivência. "Um pouco de cristianismo, um pouco de budismo, um pouco de candomblé, um pouco de santo-daime, enfim... e cada um monta a sua experiência religiosa. Porque nenhuma experiência parece suficiente para responder às ansiedades suscitadas pela crise da racionalidade." (Frei Betto, 1999, p. 29). Assim, misturam-se teses diversas na produção de uma nebulosa místico-esotérica que, desde os anos 70, não cessou de ganhar terreno.

No Brasil, as religiōes sempre tiveram um papel relevante. Atualmente há uma nova disposição decor rente, em parte, das ambivalências da modernidade. Segundo Montes (1998), as novas marcas são voltadas para a fluidez do campo religioso, o baixo grau de institucionalização das igrejas, a proliferação das seitas, a fragmentação de crenças e práticas devocionais e o rearranjo pessoal constante. Os efeitos são expressos tanto no mundo público quanto no privado. Dentre os diversos fatores destacam-se: a ampliação e diversificação dos bens de salvação - que mostram u ma nova face de um terreno que foi durante muito tempo quase que exclusivo das instituições católicas, imbricadas com a estrutura de poder de estado; e a autonomia do indivíduo de escolher livremente sua religião, ou mesmo construí-la. Daí a privatização crescente da religião. O que se constata no mundo contemporâneo é um encolhimento do universo religioso sobre si mesmo, ameaçado pelas múltiplas experiências do mundo e pela competição no interior do universo religioso em torno da tarefa de conferir significado à vida.

As novas religiosidades, "contemporâneas ao surgimento dos movimentos ecológicos, dividem sua lealdade entre as reivindicações modernas da liberação feminina e a sabedoria mais antiga de religiōes de outros povos, 
essencialmente centradas no valor da vida" (Montes, 1998, p. 144). A vida como valor em si mesma, antes presente no domínio do biopoder - exercido sobre o indivíduo e a sociedade-, torna-se elemento integrante da religião hoje. Essa característica viabiliza uma descrição da religião que a aproxima do biopoder. Nossa idéia é que a valorização da vida pela religião, aliada a outras características da nova religiosidade - como a expressão da individ ualidade, a relação com a vida privada e o cuidado com o corpo e a alma podem levar à sua inserção na gramática do biopoder. A religião hoje é formada por características que se entrecruzam com a perspectiva da religião invisível e do biopoder, com a valorização do corpo e da vida.

A importância apontada por esses autores corrobora a tese que a valorização da religião na atualidade é, talvez, uma alternativa ao mal-estar suscitado pelo biopoder. $\mathrm{O}$ cosmos sagrado da atualidade é composto por temas como a valorização das emoções e do corpo, o pragmatismo, a privatização das práticas religiosas e a subjetividade dos adeptos. Essas características conformam-se a religião invisível descrita por Luckmann. Não mais relacionadas especificamente à sexualidade e à autonomia, os temas foram pluralizados. Muitos deles estão presentes nas religiões asiáticas, o que contribui de forma significativa para o crescimento de sua recorrência no Ocidente. Os aspectos religiosos valorizados por essa tradição têm desempenhado o papel fundamental de inserção do indivíduo na sociedade. Para entender essa relação e suas conseqüências, é necessário conhecer as características das religiōes asiáticas que permeiam a visão de mundo dos ocidentais. No entanto, a pluralidade dessas religiões leva à constatação da importância de definir um objeto de estudo mais específico. Nesse sentido, destacamos o papel do budismo, pois é uma prática que se ajusta às características da religião como exercida na atualidade. Três fatores justificam essa opção. Primeiro porque o budismo coaduna-se às características de um tipo de religião que marca a atualidade, que é uma religião privatizada. Segundo porque é reconhecido o papel que a religião volta a ter na atualidade. Em terceiro lugar, porque é um instrumental que permite situar melhor a discussão desenvolvida na pesquisa. 


\section{O BUDISMO NO BRASIL}

Desde a década de 70, aumenta cada vez mais o interesse pelos ensinamentos de Buda. A estimativa do número de brasileiros budistas realizada pelo IBGE é controversa, variando de 236.408 até 1.000 .000 . Nos dados oficiais de 1991, aproximadamente 38\% desses budistas eram de origem asiática, o que pode indicar que a maior parte dos budistas brasileiros é composta de convertidos. Em 2003, Lobato ressaltou que apenas uma das linhagens - a Associação Brasil Soka Gakkai - tinha 150 mil adeptos registrados. O Templo Rio de Janeiro, da vertente Teravada, contava então com 10.000 membros e um aumento de $70 \%$ na freqüência. Outro dado relevante advém do mercado editorial. Como exemplo de extraordinário sucesso, A Arte da Felicidade, de Dalai Lama, vendeu em dois meses 180 mil exemplares no Brasil (Lobato, 2003).

Apesar do sucesso, acredita-se que o budismo é restrito a certos segmentos da sociedade. Como afirma Usarski (2002), o budismo no Brasil dificilmente será um fenômeno de massa, contudo poderá exercer influências na sociedade como um todo. Um outro fator a ser considerado é que a valorização do budismo é reconhecidamente feita, na atualidade, por pessoas que pertencem aos segmentos sócio-econômicos mais altos. Nesse caso é pertinente a afirmação de Campbell (2001) que a história intelectual tende a se concentrar na cultura "mais alta" - pois ela tem uma influência significativa sobre a formulação de ideais éticos.

De uma perspectiva mais ampla, a recorrência ao budismo comparada a outras religiōes é pequena. No entanto, algumas características relativas à realidade brasileira devem ser esclarecidas. É importante lembrar que um bom número de brasileiros freqüenta práticas religiosas de vários cultos. Conforme Antoniazzi (2003), uma recente pesquisa sobre religião mostrou que cerca de $25 \%$ dos entrevistados freqüentam mais de uma religião. Outro aspecto é que há muitos modos de praticar as religióes, mesmo dentro do próprio catolicismo. Alguns sociólogos julgam os números do IBGE, dos censos de 1991 e 2000, exagerados em relação aos católicos e inferiores com relação às outras religiōes. Apesar de freqüentar 
outros cultos, as pessoas continuam a se declarar católicas. Uma categoria do censo que deve ser explicitada é a "sem religião". Não há distinção entre os que são ateus e os que possuem algum tipo de crença. Diversas pesquisas mostram que a religiosidade entre os brasileiros continua alta. Portanto, a não-religião dos brasileiros parece indicar mais a valorização de uma "religião invisível" - como abordada por Luckmann. A adesão não é a uma religião institucionalizada, mas a uma crença em algo superior que dá sentido à vida.

O budismo é marcado, histórica e socialmente, por uma intensa diversidade interna de variações étnicas, doutrinárias, filosóficas e rituais. Usarski (2002), Shoji (2002) e Santos (2003) relatam diferentes sistematizações sobre o budismo no Ocidente.

Existem pontos que marcam uma tipologia mais estritamente brasileira. Usarski (2002) reuniu significativo material da análise e de pesquisa acerca do budismo no Brasil. Para o autor, a situação atual da pesquisa sobre esse tema é consideravelmente atrasada. Não existe registro da valorização do budismo antes dos anos 60, como ocorreu nos Estados Unidos e Europa. Em relação ao interesse dos brasileiros, pode ser notado um crescimento nos anos 60 , mas a única iniciativa mais institucional foi a criação formal da Sociedade Budista Brasileira (SBB). O budismo de conversão de primeira geração, como é designado, é decorrente, em grande parte, do investimento de alguns intelectuais que tratavam o budismo sob uma abordagem mais erudita, individual e universalista. Por isso, ele o define como um budismo de intelectuais. Foram basicamente as teias de relacionamento sociais estabelecidas pelos representantes dessa fase que estruturaram a religião budistano Brasil(Albuquerque, 2002; Gonçalves, 2002; Matsue,2002). A segunda geração, desenvolvida a partir dos anos 70 , é marcada por uma maior diversidade dos adeptos, dispersão geográfica e heterogeneidade de doutrina. Seu impacto é mais significativo, decorrente principalmente da pregnância do caráter internacional e globalizado. Três subcategorias representam exemplarmente essa geração: o zen-budismo, o Sôka Gakkai e o budismo tibetano. Muitos dos que se interessaram pelo budismo nesse momento estavam associados ao movimento teosófico e aos hippies. 
A partir desses dados, Shoji (2002) categorizou as vertentes do budismo no Brasil voltadas para a motivação, para a conversão e o tipo de prática realizada. A primeira categoria é a do budismo intelectualizado, que procura o aperfeiçoamento espiritual e intelectual e tem interesse cultural pelo exótico e pelo esotérico; a segunda é o budismo de resultados, influenciado pelas religiôes populares brasileiras, que são motivados principalmente por problemas de ordem prática (saúde, finanças e família). O budismo de resultados tem como preocupação central o sofrimento, por isso há a valorização da recompensa e do karma. Historicamente a resolução de problemas a partir da religião é comum no Brasil.

O processo de valorização do budismo na realidade brasileira caracteriza-se pelos seguintes dados: é mais restrito às classes média e alta; tem sofrido grande influência do budismo desenvolvido nos Estados Unidos; foi impulsionado pelo interesse pela cultura japonesa e pela prática de artes marciais japonesas; é muito motivado pela atração pelo exótico; são influenciado s pela globalização, mas em geral são interpretadas de acordo com os referenciais do ecumenismo e sincretismo brasileiro. Atualmente, os convertidos utilizam uma pluralidade de referências, com uma marca cada vez mais yuppie. Para melhor entender a imagem que é transmitida aos interessados no budismo no Brasil, pesquisamos na Internet os sites relativos ao tema. ${ }^{2}$

\footnotetext{
${ }^{2}$ A pesquisa foi realizada nos anos de 2003 e 2004 . Encontramos 177 sites cadastrados em português sobre o budismo, apesar de não estar disponível o acesso a grande parte deles. Os demais podem ser divididos em duas grandes categorias: os de grupos de praticantes ou estudiosos no tema; e os pessoais, que geralmente misturam temas diversos com o budismo, vistos como diferentes recursos para o bem-estar. A partir da primeira categoria descrita, tentaremos uma aproximação do vocabulário utilizado para a prática do budismo no Ocidente. Como fonte complementar a essas informaçôes, utilizamos livros do Dalai Lama traduzidos para o português, por ser este o representante maior do budismo tibetano - vertente de gran de expressão en tre os convertidos no Brasil. É importante salientar que estamos utilizando o budismo como uma grande categoria em função do limite da pesquisa realizada, mas reconhecemos que existem diferenças significativas entre as diversas vertentes existentes.
} 
As características encontradas nos sites corroboram, em parte, a afirmação de König e Waldenfels (1998) de que a atração que o budismo exerce no Ocidente atualmente é voltada especialmente para três questões centrais: a psicologia sutil, a cosmovisão holística e os exercícios de meditação. Do nosso ponto de vista, três outras complementam o quadro de referência do budismo no Ocidente: o pragmatismo, a relação com a ciência e o valor concedido ao corpo. Essas características articulam-se com duas categorias que consideramos importantes na atualidade: a religião invisível e a importância do corpo. Na pesquisa realizada os conteúdos dos sites foram distribuídos em torno dessas duas categorias. Explicitaremos, no presente artigo, a categoria da religião invisível.

\section{O BUDISMO E SUAS INTERCONEXŌES NA ATUALIDADE}

Pela relação com a atualidade e importância descritas, o eixo de análise privilegiado nesse artigo valoriza o budismo como uma religião invisível. Dessa perspectiva, o budismo é visto como componente do cosmos sagrado da atualidade. Os principais aspectos que contribuem para essa afirmação são: o exercício a nível individual, privado, reconhecido como uma psicologia budista; o pragmatismo desse tipo de religião, fundamentada em regras úteis para o mundo; e a relação com outras pessoas e com o universo, que enaltece uma cosmovisão holística.

O primeiro item que destacamos é a da psicologia budista, encontrada em diferentes conteúdos. Podemos, por exemplo, relacionar ao significado do termo "Buda". A preocupação mais recorrente nos sites é mostrar que qualquer ser pode atingir o nível superior de entendimento e de plenitude da condição humana, a Iluminação. Apesar da idéia de que é acessível a todos, também informam que ele é aplicado às pessoas excepcionais que atingiram um tal grau de elevação moral e espiritual. De forma geral, divulgam que os ensinamentos budistas proclamam o despertar do potencial dentro de cada ser humano e fornecem um método prático para fazer isso. "Um modo de vida que pode ser seguido, praticado e desenvolvido por 
qualquer indivíduo. É uma disciplina do corpo, da palavra e da mente.” (<http://www.brasil.terravista.p๖, acesso em 13/09/2003). Paraser um Buda é necessário transformar a mente, eliminar a energia negativa e converter-se em um ser completo e perfeito.

Portanto, a disciplina corporal e espiritual é a única condição para a conquista da Iluminação. Fator que torna o budismo uma prática pertinente no mundo atual. Em primeiro lugar porque coloca o sujeito como único responsável pelo acesso a uma condição superior. Depende apenas de si mesmo. É o homem quem traça a rota do seu próprio destino. Um segundo aspecto é o tipo de exercício que é exigido: a disciplina. Não é uma disciplina imposta por qualquer alteridade. Os exercícios são regulados pela própria vontade. Por fim, o corpo é valorizado como um item central desse exercício. $\mathrm{O}$ que possibilita a ligação do budismo às bioasceses atuais. Para ser um iluminado é necessária uma disciplina que também é corporal. Disciplina corporal que inclui não apenas a sexualidade, mas a alimentação, os exercícios. O corpo é, assim, o meio que permite o acesso à Iluminação. Se compararmos com os estudos foucaultianos das asceses clássicas, podemos dizer que é um exercício que, de certa forma, assemelha-se à dietética. É uma preocupação com o regime corporal que visa a outros fins, não apenas o culto ao corpo. Por outro lado, o acento sobre o corpo e os sentidos coaduna-se ao entendimento relativo às religiōes atuais (Champion, 1990).

A vida do Buda - chamado de Sidarta Gautama ou Siddhartha Gautama -, reconhecido como o fundador do Budismo, também é uma referência comum nos sites. Sua história é contada de forma a mostrar a importância da busca pessoal no sentido da vida. "Sidarta transformou-se no Buda em virtude de uma profunda transformação interna, psicológica e espiritual, quealterou toda a sua perspectiva de vida." (<http://www.budismo.com.br $>$, acesso em 12/09/2003). O sentido da vida e o valor a ela vinculado, um dos grandes objetivos perseguidos pelo budismo, é visto por Montes (1998) como elemento integrante das religióes hoje.

O Buda nasceu em torno de 556 a.C. em Kapilavastu, no norte da Índia, atual Nepal. Ele abdicou do conforto e riqueza de sua família para se dedicar à busca da verdade. Assim, Buda estimulava o autodesenvolvimento. 
Mediante o próprio esforço e dedicação, o homem tem em suas mãos o poder de se libertar da escravidão, da ignorância e do sofrimento. $\mathrm{O}$ budismo ensina o homem a ser seu próprio mestre, a se destituir dos condicionamentos, dos preconceitos, a não permanecer dependente de cultura ou análises intelectuais. Portanto, a idéia de disciplina é reforçada e sua dependência exclusiva do praticante é enaltecida.

Também a noção de religião mística, definida por Troeltsch, pode ser vislumbrada a partir dessas afirmações. As características de possuir um sistema de crenças próprio, conceber o divino como impessoal, a ausência de uma única verdade, o sincretismo e o individualismo, estão presentes nos discursos sobre o budismo. $\mathrm{Na}$ acepção de Troeltsch, o místico é visto como o que penetra o sentido aparente das coisas para possibilitar a percepção da realidade profunda.

O entendimento da realidade profunda no budismo é viabilizado pelo autoconhecimento, temática também pertinente à atualidade. Por meio do autoconhecimento - tão caro ao Ocidente - vive-se com discernimento e sabedoria, elimina-se as causas que são as raízes de nossos medos, complicações e prisões. O patriarca do Templo Higashi Honganji, mestre Shinran, considera que a verdadeira felicidade só pode ser alcançada pela descoberta do autêntico significado da existência, o que é viabilizado pela consciência da motivação advinda da nossa interioridade. As raízes do mal estão na ignorância, causa das idéias errôneas. Para progredir,precisamos libertarmonos da dúvida e para isso é necessário ver claramente, o que só é possível qua ndo a Verdade vem através da visão interior, adquirida pelo autoconhecimento. "O budismo é um caminho que conduz à compreensão da Realidade Última, à liberdade, à felicidade e à paz, mediante a perfeição moral, intelectual e espiritual" (<http://www.brasil.terraavista.pt >, acesso em 13/09/2003).

O entendimento do sofrimento é uma contribuição de destaque no âmbito da psicologia. A valorização do budismo pelos ocidentais está intimamente relacionada ao sofrimento. A crença de que a plenitude é acessível a todos se tornou lugar comum na contemporaneidade. Conforme constatou Bruckner (2000) - o que, de certa forma, corrobora as análises sobre a 
moralidade de Taylor (1997) -, o dever de felicidade é uma ideologia própria à segunda metade do século XX. O enaltecimento do prazer e a rejeição do sofrimento são seus principais ditames. Mas esse ideal foi transformado numa penitência. Quando o objetivo da vida passa a ser o bem-estar, qualquer contrariedade é inter pretada como uma afronta. Como afirma Bruckner, "a sociedade da felicidade proclamada tornar-se-ia pouco a pouco uma sociedade mal-assombrada pelo desespero, perseguida pelo medo da morte, da doença e do envelhecimento." (2000, p. 54). Uma particularidade do dever de ser feliz é que ele é de responsabilidadedo próprio sujeito. Essas características da valorização da felicidade na atualidade são encontradas no budismo. A imagem que muitos têm é de que através da prática budista é possível superar o sofrimento e alcançar a felicidade. Nesse sentido, poderíamos dizer que o budismo permite o exercício de uma função terapêutica, que marca as religióes contemporâneas (Julliard, 2000).

Segundo o Dalai Lama (2001, p. 31), "o sofrimento é a revelação do budismo. Sofrimento físico, mas também sofrimento moral, sentimento de impotência, de frustração, de inutilidade dentro deste mundo". Na perspectiva budista, dor e sofrimento são fatos inalienáveis da vida e estão divididos em duas categorias que se relacionam: as formas evitáveis, que surgem em consequiência de fenômenos como guerras, pobreza, violência, crime e até coisas como o analfabetismo e certas doenças; e as formas inevitáveis, que incluem os problemas relacionados a doença, velhice e morte.

No tratamento que o budismo emprega para o sofrimento, há uma certa crítica à concepção adotada na atualidade. Conforme encontrado nos sites, o mundo moderno favoreceu a crença de que o sofrimento e a insatisfação provêm apenas de causas exteriores. Por isso é comum a luta pela mudança das condiçóes exteriores, na intenção de que ao se manifestarem de forma propícia, seja alcançada a felicidade. Para o budismo, o problema maior é que todas essas questôes são mutantes. Por isso, mesmo com o alcance desses objetivos, as pessoas continuam insatisfeitase infelizes. Aquele que visa apenas objetivos exteriores, como honrarias ou posição social, acaba esgotando-se em fadigas inúteis e vãs. No entanto, cair na tentação de considerar que o mundo interior pode ser fonte exclusiva de prazer tam- 
bém é insatisfatório. A causa da infelicidade não deve ser buscada exclusivamente no exterior nem no interior.

O budismo também aborda a importância de não considerar a felicidade como um estado permanente. Esse aspecto é uma marca do mundo atual. A centralidade das referências corporais - que não são fixas -, e as constantes transformações decorrentes do consumismo e da economia de mercado, mudam em alta velocidade os parâmetros da sonhada felicidade. Ao enfatizar que qualquer experiência, mesmo que traga felicidade, não perdura, o budismo dá suporte ao sujeito para entender uma situação comum vivenciada na atualidade.

Diante do exposto, podemos dizer que a concepção de sofrimento e felicidade do budismo é adequada aos tempos atuais e tenta dar suporte ao indivíduo para que ele supere a dicotomia exercida sobre esses termos pelo mundo ocidental contemporâneo. O que é postulado pelo budismo não é negar o sofrimento, mas admitir sua existência como condição do ser humano. Dessa forma é possível alcançar a felicidade. Comparada ao dever da felicidade, é uma premissa que tem mais chances de não causar frustração, visto que é congruente em suas afirmações. Como afirma Bruckner (2000), o dever de ser feliz suscita três paradoxos: primeiro, a abstração inerente ao conceito de felicidade, que ao mesmo tempo em que seduz, causa angústia - não há como ter certeza da verdadeira felicidade; o segundo paradoxo é relativo à sua relação com a banalidade; por fim, ele termina por recorrer àquilo que deveria evitar, de tanto procurar a felicidade, encontra-se o sofrimento - seja pela eterna procura ou pelo fracasso da procura. A abordagem que o budismo faz desses termos seria um meio de superar tais paradoxos engendrados na contemporaneidade. Nesse sentido, é importante lembrar que a preocupação com o sofrimento é um dos principais motores para a conversão ao budismo.

A busca é por orientaçôes sobre aspectos da vida que levam ao sofrimento. São geralmente questóes cotidianas ou imediatas, que preocupam as pessoas e as fazem buscar soluçóes. A mente iluminada deve ter generosidade, tolerância,ética, energia inflexível,concentração meditativa,sabedoria, amor, compaixão, alegria, equanimidade e verdade. A valorização desses 
traços não é uniforme. As qualidades do ser humano que são exaltadas nos sites geralmente referem-se àquelas que são mais escassas no mundo ocidental contemporâneo. Reforça, assim, a idéia de Lobato (2003) de que uma das principais razões do engajamento dos ocidentais é o compromisso com as necessidades do dia-a-dia. E confirma a vertente, formulada por Shoji, do budismo de resultados existente no Brasil.

Os conteúdos citados, que compóem a psicologia budista, demonstram o uso privado do budismo - característica central mencionada por Luckmann na definição da religião invisível. Os enunciados expressam que o budismo possibilita a homem experimentar e construir por si o conjunto de suas motivações religiosas. Como o cosmos sagrado atual permite a recorrência a temas heterogêneos ao religioso, cada um pode compor seu universo de sentido de forma particular - abertura para a variedade de fontes que o budismo valoriza.

Essas consideraçôes levam ao segundo item relativo à vertente de análise da religião invisível: o pragmatismo. O budismo no Brasil é praticado de formas diversas, que não necessariamente estão preocupadas com os fundamentos da religião, mas principalmente com o uso pragmático que pode ser feito em termos de resultados práticos para a vida.

O budismo rejeita qualquer fé prévia. Crer é aceitar o que não sabemos se realmente existe. Não é o testemunho escrito ou a autoridade de mestres e sacerdotes que deve levar à crença, mas o que se enquadra na razão de cada um. O budismo é baseado na visão das coisas pelo conhecimento e compreensão, e não pela fé ou crença cega. A valorização recai sobre os fenômenos que podem ser vistos, tocados e compreendidos. A palavra sânscrita sraddha, que geralmente é traduzida por crença, significa primeiramente "confiança nascida da convicção".

Assim, a fé cede lugar à confiança baseada no conhecimento. Deve-se crer no que a prática mostra que leva ao bem, de si mesmo e dos outros. Foi a partir de sua vivência que Buda pensou nos seus ensinamentos. Daí a flexibilidade da tradição budista, que vem da experiência. $\mathrm{O}$ mundo passa por constantes mudanças. Não há nada fixo. Todo ensinamento, portanto, é relativo e impermanente. Não é uma palavra divina, imodificável. Pri- 
meiro os budistas estabelecem os fatos, depois tentam analisar suas causas, sem perder de vista a interdependência e a impermanência. A partir disso, se for pertinente, mudam de atitude. É uma atitude positiva e pragmática, que pressupõe a constante discussão sobre as maneiras de pensar e agir. Para o Dalai Lama, essa é a espinha dorsal do budismo, a conjunção do rigor com a flexibilidade. Por isso não há uma verdade única, o que é mais uma crença adequada ao mundo contemporâneo.

A abertura para diferentes grupos e o pragmatismo do budismo leva a uma perspectiva de que para adotá-lo não é necessário despir-se dos valores da própria cultura. $\mathrm{O}$ que possibilita uma inserção no Ocidente que, se por um lado aproveita tópicos que permeiam a sociedade contemporânea, por outro pode adequar-se no que extrapola o interesse dos ocidentais. Em relação ao Brasil,podemos dizer que essas características reforçamo sincretismo existente. Como relatou Antoniazzi (2003), um número significativo de praticantes utilizam crenças religiosas diversas. O budismo, portanto, pode ser inserido nesse quadro de referências, mesmo porque não demanda exclusividade nem lida com verdades absolutas.

O pragmatismo presente no budismo leva, por outro lado, a uma pluralidade de usos. Segundo Lenoir (<http://www.revistaepoca.globo.br>, acesso em 30/10/2003), o desenvolvimento do budismo no Ocidente não é homogêneo. Na pesquisa realizadapelo autor, é possível encontraros diferentes tipos de praticantes citados anteriormente. Ele avalia que o pragmatismo aliado à valorização da espiritualidade e ao tratamento tolerante de temas pertinentes ao mundo atual são os grandes motores da recorrência à prática budista. Não há deidade a qual satisfazer, figura salvadora a qual rezar, ritual para satisfazeràs exigências dos deuses, hábito periódico para assegurar a proteção divina. A responsabilidade pela vida é do indivíduo, de sua capacidade de conhecer, purificar e transcender sua própria natureza. A ação responsável e refletida é que pode modificar a realidade. A adaptabilidade às constantes mudanças é um fator importante para os ocidentais, visto que a instabilidade e a impermanência são marcas da sociedade contemporânea.

O terceiro aspecto que compõe o eixo de análise da religião invisível é a relação com outras pessoas e com o universo. A idéia que o budismo é 
uma religião que gera resultados pessoais e sociais práticos e observáveis para um maior número de pessoas possível também está vinculada a ações que consideram o outro. Em uma escala social maior, alguns sites preocupam-se em se vincular com propostas de ações sociais.

A melhora da própria vida e da vida dos outros é interpretada como mais um dos grandes atrativos do budismo. É uma forma de investir em si mesmo e no outro, sair do egoísmo e criar laços, o que pode ser visto como uma alternativa à biossociabilidade. A incapacidade de suportar a visão do sofrimento dos demais serve como base para a ética budista. Só é possível ser útil a si mesmo se for também aos outros. Ao se preocupar com o outro, há o cuidado indiretoconsigo, o que é uma garantiapara não prejudicar ninguém. Para tanto, é preciso atentar para os sentimentos das pessoas, o que é possível por meio da empatia. A capacidade de empatia é necessária para a ética, pois é por meio dela que despertamos para o amor e a compaixão.

O caminho da libertação de toda a humanidade está na perseguição da própria salvação. Mas não se deve confundir com uma perspectiva individualista. $\mathrm{O}$ conceito de origem dependente pode esclarecer a explicação do budismo. Há três níveis de entendimento para as ocorrências no mundo. $\mathrm{O}$ primeiro está relacionado ao princípio de causa e efeito. Tudoé decorrente de uma complexa rede de causas e condições relacionadas. O segundo nível diz respeito à ausência de autonomia entre as partes e o todo. Por fim, nenhum fenômeno tem, em essência, identidade independente. A partir dessas afirmações, as noções de eu e de mundo ganham um significado particular no budismo. Uma conseqüência é a avaliação de que o universo é um todo, que qualquer atitude ou pensamento de uma pessoa repercute sobre as demais e sobre o mundo. A satisfação individual está relacionada ao bem-estar dos outros e do ambiente em que se vive. Um outro fator é que a representação da realidade é modificada, com tendência a ver as coisas de forma mais ampla e integrada.Por fim, há a inclinação para perceber o mundo como um encadeamento. Assim, nem mesmo a individualidade existe no modo como geralmente é pensada. $\mathrm{O}$ eu é uma síntese mental advinda de uma série de acontecimentos complexos, referido sempre a uma alteridade. Por isso, o eu é uma ilusão. Não há nítida distinção entre o eu e o outro. 
A relação com o outro é, no nosso enfoque, um aspecto imprescindível dentro do quadro de referência para a atualidade. A sociedade ocidental moderna é indiscutivelmente marcada pelo individualismo e consumismo. Como indicado por Calligaris (1996), Costa (1986), Dumont (1985) e Lasch (1983; 1986), o homem é profundamente indiferente a tudo que não seja do interesse dele mesmo. Podemos considerar como uma cultura narcisista que expressa um individualismo exagerado. Nesta cultura, o objeto torna-se o espelho do sujeito e expressa a imagem perfeita do desejo do indivíduo. É a contraface de uma sociedade onde mercado, consumo, objeto e lucro são as palavras de ordem. O consumismo altera substancialmente a imagem que o sujeito tem de si. Costa (1986) relaciona esta alteração na identidade do sujeito às necessidades de uma sociedade capitalista com valores produtivistas. É a representação possível de um sujeito que atende às necessidades político-econômicas do capitalismo tardio. Nessa cultura, tornou-se comum lidar com as pessoas da mesma maneira com que se lida com objetos. O que possibilitou a construção de um contexto onde é cada vez mais difícil investirmos no outro. Esse panorama foi analisado e criticado por muitos autores, como também foram vislumbradas dive rsas perspectivas de superação do investimento exclusivo em si mesmo. No horizonte de alternativas que viabilizam melhores opções, o budismo pode ser uma referência interessante. Nele não há o desinvestimento em si, o que seria uma proposta muito próxima da realidade atual. Mas o si não pode ser entendido sem a referência ao outro.

De acordo com o budismo, para ter uma vida satisfatória é necessário não apenas boa comida, boas roupas e bom abrigo, mas também uma boa motivação: a compaixão. A compaixão dissolve a tendência ao egoísmo e sensibiliza o indivíduo para perceber as necessidades do próximo. Assim é possível respeitar os direitos dos outros e a dignidade humana. A compaixão leva à compreensão do sofrimen to e da dor do mundo e atua convenientemente para eliminar suas causas. Para desenvolver a compaixão é necessário ser tolerante e paciente. Na prática da tolerância até mesmo o inimigo pode ser um grande professor. $\mathrm{O}$ altruísmo é um dos principais pilares do budismo. 
Além da compaixão, a liberdade e igualdade também são vistas como fundamentos básicos que servem para guiar as relações. Como citado anteriormente, um grande atrativo do budismo é que qualquer pessoa pode ascender à natureza do Buda. Se todos têm essa capacidade, ninguém deve ser discriminado ou visto como inferior. As práticas das pessoas, sejam elas sexuais ou não, não se prestam a ser critério único e decisivo para a avaliação moral. $\mathrm{O}$ que faz com que as pessoas sintam-se no meio de iguais. As idiossincrasias são respeitadas. Em um mundo que incita a cada ser buscar sua singularidade e autoprodução, essa é uma característica importante. A liberdade e o respeito ao outro servem como apoio para demonstrar as próprias singularidades. Portanto, podemos dizer que no budismo é possível encontrar respaldo moral para assumir as próprias inclinaçôes, a partir da defesa ao respeito máximo pela vida. $\mathrm{O}$ respeito ao outro e ausência de verdades absolutas pode relativizar o sofrimento das pessoas.

De acordo com essas afirmações, o budismo vai além da exclusiva busca da unidade suprema - conforme afirmou Cailliau (2003). É inegável que exista algum tipo de preocupação com o outro e o engajamento no mundo. A noção de Karma, por exemplo, revela esse valor. Noção essencial para entender a defesa que o budismo faz da preocupaçáo consigo e com o outro, o Karma é uma palavra sânscrita que significa ação. Lei natural de ação e reação, ela demonstra a importância da noção de causalidade nos ensinamentos budistas.

O Karma é uma das idéias budistas mais difundidas no Ocidente. Encontramos praticamente duas versōes sobre o tema. A primeira delas, e a mais difundida, descreve-o como uma espécie de herança para as próximas encarnações. Tudo o que se faz hoje retornará na próxima encarnação. Pode ser visto como uma forma de evitar uma ação responsável ou aceitar as coisas como estão, por não poder alterar a herança de vidas passadas. Mas também pode ser percebido como um incentivo para aproveitar o presente de forma criativa e positiva, e, dessa forma, regular as ações de forma responsável. O Karma determina o destino de cada um, afinal, nada existe que não esteja relacionado com a sua própria causa.

A segunda acepção não relaciona o Karma à reencarnação. Nessa pers- 
pectiva, a idéia ocidental da reencarnação - a de que uma alma ou "espírito" imutável ocu pa diferen tes corpos hu manos indefini damen te - não existe no budismo, mas são decorrentes das concepções espíritas surgidas no fim do século XIX. O renascimento ensinado pelo budismo é completamente diferente da reencarnação. Na tradução que os ocidentais fizeram do budismo, eles foram influenciados pelas suas próprias concepções, o que teve como resultado um engano sobre esse tema que permanece nos que estudam o budis mo superficialmente, principalmente no Brasil. Não há reencarnação no budismo, pois não há entidade espiritual imutável. O budismo não constrói a dicotomia entre um corpo perecível de um lado e uma alma eterna de outro. Renascimento significa para eles a transmissão ou influência das açôes intencionais nos seus frutos. Toda ação intencional, para o bem ou para o mal, gera conseqüências.

No que diz respeito ao Karma, o Dalai Lama alerta para a importância de ter claro que, apesar da consideração de que os sofrimentos fazem parte da natureza humana, podemos agir sobre eles. O sofrimento é conseqüênđa do Karma, mas nem tudo que vivemos é predeterminado. Até porque podemos mudaro nosso Karma a partirdos próprios atos no mundo. Porisso, é inadmissível quea noção sirva dedesculpa,como o fazem tanto ocidentais como orientais, para se eximir das responsabilidades. Os seres humanos não são impotentes diante da vida. Há muito que fazer para alterar a própra existência. Mesmo o que é inevitável, tem-se o poder da escolha na maneira como reagir.

A idéia descrita advém da visão holista recomendada pelo budismo: o Universo é unidade da qual o homem faz parte, nada existe separado do todo. Qualquer mudança em uma parte, afeta o todo e vice-versa. A vida é uma só e toma formas diferentes, mas estreitamente dependentes e ligadas entre si. É impossível perceber a própria existência se não compreendemos a rede de causas e efeitos na qual está aprisionada. Portanto, a percepção da própria existência está diretamente ligada à existência de todas as outras coisas. $\mathrm{O}$ conceito de interdependência é visto como um dos motivos determinantes que levou à atração do budismo pelo Ocidente. É uma forma de responsabilidade universal por todas as coisas, a tomada de consciência de cada um como membro da família humana, construtores da paz e protetores dos seres. 
Para o Dalai Lama (2003), o estímulo pela responsabilidade universal é fundamental. Para alcançá-la é necessário primeiro o desarmamento interno, que tem como reflexo o desarmamento externo. O que fazemos reflete em todo o universo. Essa atenção que não se restringe a si mesmo e a grupos particulares vai além da biossociabilidade.

A preocupação com a ecologia, cada vez mais presente no Ocidente, também encontra respaldo no budismo. Alguns sites citam a importância da natureza e da nossa relação com o meio como um dos aspetos imprescindíveis para superar o sofrimento. As posiçôes ecológicas do Dalai Lama estão inscritas no que o budismo tem de mais profundo, que é o respeito a toda forma de vida (Guimarães, <http://www.budaeobudismo.com.br>, acesso em 07/09/2003).

As idéias de ação responsável, valorização do outro e do mundo, responsabilidade universal, entre outras citadas, estimulam a questionar a classificação que Weber realizou do budismo. O budismo era entendido como exemplo da mística extramundana, pois funcionava como uma fuga contemplativa do mundo. Se reconhecemos o papel que a ação tem hoje no budismo, podemos dizer que seu uso no Ocidente intercala ascetismo e mística, ou seja, ação e contemplação, em relação à salvação. Poderia ser entendida hoje como uma religião místico-ascética extramundana.

A transcendência valorizada pelo budismo ajusta-se tanto a noção de religioso de Luckmann - como algo que permite ao ser humano transcender sua natureza biológica -, como a proposição de Berger de contemplar universos de significado moral. A idéia de religião de ambos também é referida às formas sociais de religião. Perspectiva que concede importância aos fenômenos individuais, mas sem desvincular tais fenômenos do repertório disponível em uma dada sociedade. Nessa direção, nosso próximo eixo de análise enfatiza outro parâmetro essencial para a sociedade atual: o valor do corpo.

A partir dos resultados encontrados na pesquisa dos sites é possível dizer que a extrema valorização do corpo existente na atualidade encontra respaldo no budismo. Aliado à gramática da religião invisível, haveria o corpo, valorizado como referente determinante para as subjetividades con- 
temporâneas. Portanto, o budismo poderia ser situado na junção desses dois eixos de significados que fazem parte do universo de sentido dos sujeitos na atualidade. Uma coincidência histórica que não parece ser aleatória.

Bioidentidade, biossociabilidade e bioasceses encontram equivalentes no budismo. Ao analisar os impasses decorrentes da nova configuração do biopoder a partir da gramática budista, vislumbram-se opções para uma superação da problemática do sujeito hoje. Primeiramente, o universo imanente do biopoder tem afinidade eletiva com a transcendência considerada pelo budismo. Portanto, os referentes do budismo podem funcionar como um objetivo transcendente nas práticas da bioascese. Em segundo lugar, com a remodelação da categoria tradicional do político, o budismo pode servir como substituto para esse domínio, apesar de não estar diretamente articulado a um programa de ação política ou social. A imagem difundida no Ocidente do budismo possui características que incentivam o investimento no outro e, por não ser um projeto hegemônico, viabiliza a pluralidade. Por fim, no âmbito da moralidade, o budismo tem uma ética aberta e fornece uma moral possível e adaptada aos tempos atuais.

O budismo dá margem para que a realização pessoal seja vinculada a outros princípios fundamentais, inclusive sociais. Assim, é factível preservar a dimensão do experencial, tão cara ao Ocidente, com valores morais e coletivos. As fontes morais podem ser pluralizadas e mais adaptáveis aos tempos atuais. Afinal, a ética budista tem uma afinidade eletiva com o espírito contemporâneo.

Mas é importante salientar que não necessariamente a recorrência à religião esteja desempenhando tal função. Pelo contrário, se for tomado por referência as características do budismo encontradas nos sites, possivelmente essa religião também funciona hoje como um item de consumo para a cultura das sensações. Os valores recomendados podem ser apenas um meio para a auto-realização. A religião na atualidade parece ajudar aos sujeitos na criação de uma ascese religiosa que pode dispensar a realização de projetos coletivos. Dessa forma, muitas vezes a antropologia budista é esquecida.

O que pode ser indagado é a plausibilidade de não ser influenciado, atualmente, pela cultura do consumo e das sensaçôes. Criar um mundo à 
parte dessa realidade serve hoje como uma utopia, um horizonte ao qual é viável utilizar como referência para criticar as vivências. Nesse sentido, as idéias de Arendt (1999) são exemplares de uma sociedade onde a condição humana pode ser pensada para além da sobrevivência. Para superar uma prática que é pautada na mera existência do corpo nu, é necessário também recorrer aos aspectos que incluem a coletividade, a ação no domínio público.

O budismo surge, então, como uma alternativa, não apenas em termos utópicos, mas também factuais. Idealmente, é plausível pensar, por um lado, no exercício do budismo sem o pano de fundo da sociedade consumista e, por outro, sem a existência daqueles que precisam lutar apenas para sobreviver. No horizonte do possível, o budismo dá margem a pensar na viabilidade de um tipo de prática corporal que, tanto no nível político como moral, tem conseqüências positivas. Inicialmente, porque o exercício corporal exaltado pelo budismo não está relacionado a uma prática ascética que visa uma forma determinada do corpo. A busca é por um equilíbrio pessoal que não diz respeito a um único ideal, mas que é dado pelas circunstâncias. Como não há referência fixa para o corpo, o eugenismo deixa de ser visto como um tópico intrínseco a essa gramática.

Por outro lado, os projetos coletivos exercidos dentro do cosmos sagrado relacionado ao budismo são meios viáveis para o investimento real no outro. O político pode ser redefinido, sem ser reduzido ao biopolítico. Os laços sociais podem ser possibilitados pela moralidade, e não se reduzirem à biossociabilidade. O budismo permite uma construção simbólica do corpo sem dissociar o indivíduo da comunidade. Dessa forma, é possível construir uma ascese da alma que valoriza o corpo, utilizando uma pluralidade de mediadores, como os que são encontrados na religiãobudista hoje exercida no Ocidente. A vida lograda pode ser, assim, desvinculada de um modelo único e pluralizada em vias que possam contemplar a diversidade das subjetividades contemporâneas.

Mas a gramática budista enuncia ainda um tópico a ser destacado. A preocupação com o corpo, a impermanência e o risco, três marcas do biopoder hoje, são conteúdos no budismo de um discurso que não é paralisante. Ao contrário, são utilizados como motores para a ação sobre si. 
Nesses termos, o corpo pode ser visto como um referente edificante na constituição das subjetividades.

\section{CONSIDERAÇÕES FINAIS}

Para finalizar, é importante situar o universo no qual essas possibilidades estão inseridas.É inviávelpensar em alternativas concretasde experiências que não tenham por pano de fundo a sociedade na qual se vive. $\mathrm{O}$ individualismo e o consumismo marcam a época de hoje e interferem em todos os níveis da existência. Nesses termos, duas questõespodem ser depreendidas, que são muitas vezes ofuscadas nos debates sobre o biopoder na contemporaneidade. A primeira é a tendência a diminuir a complexidade do mundo presente e fazer do biopoder causa privilegiada do esvaziamento da política e da moral. Diversos outros aspectos estão implicados nessa configuração, e o biopoder, no máximo, pode ser apontado como um dos fatores causais. A segunda questão é relativa à constatação que não apenas a religião, para ter sentido atualmente, tornou-se invisível. A moral e a política também são passíveis de serem privatizadas e colocadas sobre o domínio das decisóes do indivíduo. Dessa forma, a recorrente afirmação de que a ação política, a deliberação e decisão moral, e a prática religiosa não têm lugar na contemporaneidade torna-se sem propósito.

Podemos perceber nos grupos de solidariedade, cidadania responsável e programas de voluntariado, por exemplo, ações no domínio do político. Há a consideração ao outro, mesmo que seja nos moldes do individualismo. Existe, portanto, disparidade entre a afirmação que a política não tem mais sentido e a declaração que o espaço da ação política individual foi diminuído. Se a crença é na diminuição do espaço do político, pluralizar os meios de participação coletiva já é um bom começo para a redefinição da realidade atual.

Em termos da moralidade, o sentido da vida tem hoje um valor que provavelmente seria ininteligível em épocas antecedentes. Mas para julgar a plenitude ou nulidade da vida é necessária uma configuração que defina 
seus referentes. Essa configuração existe na atualidade. $\mathrm{O}$ universo de sentido construído a partir de referentes corpóreos e científicos pode ser coerente, ele não é por si inexeqüível. A dificuldade apresenta-se quando há a ocorrência de valores contraditórios, que causam uma dissonância cognitiva.

A pergunta é: o domínio do invisível pode ser apreciado em termos qualificativos? Não há respostas, nesses termos, absolutas. O entendimento dos parâmetros que ligam o indivíduo à sociedade é primordialmente útil para os envolvidos no debate. Permite, no mínimo, conhecer melhor a complexidade da atualidade e o universo de alternativas para o sujeito construir um cosmos sagrado que conceda significado último à vida, seja ele religioso ou não. É importante salientar que a condição para julgar a validade de qualquer coisa no mundo é adotar algum critério. Provavelmente, a promessa de um mundo melhor está ligada a plausibilidade da idéia de que a busca da felicidade passa por algo além da instrumentalização do próprio corpo. Nesse sentido, o resgate de determinados itens dos domínios da religião, da política e da moral pode levar à consagração de uma vida mais significativa para o sujeito contemporâneo.

\section{REFERÊNCIAS}

ALBUQUERQUE, Eduardo. Um mestre zen na terra da garoa. In: USARSKI, Frank (org.). O budismo no Brasil. São Paulo: Lorosae, 2002.

ANTONIAZZI, Alberto. As religiōes no Brasil segundo o Censo de 2000. In: Rever: Revista de Religião. São Paulo: PUC-SP, 2003, ano 3, n. 2.

ARENDT, Hannah. A condição humana. Rio de Janeiro: Forense Universitária, 1999, 9. ed.

BETTO, Frei. A crise da racionalidade e a emergência do espiritual. In: BOFF, Leonardo e BETTO, Frei. Mistica e espiritualidade. Rio de Janeiro: Rocco, 1999.

BRUCKNER, Pascal. L'euphorie perpétuelle: essai sur le devoir de bonheur. Paris: Grasset, 2000. 
CAILLIAU, Hesna. L'esprit des religions: connaître les religions por mieux comprendre les hommes. França: Éditions Milan, 2003.

CALLIGARIS, Contardo. Crônicas do individualismo cotidiano. São Paulo: Ed. Ática, 1996.

CAMPBELL, Colin. A ética romântica e o espirito do consumismo moderno. Rio de Janeiro: Rocco, 2001.

CHAMPION,Françoise e HERVIEU-LÉGER,Danièle (org.). De l'émotion en religion: renouveaux et traditions. Paris: Éditions du Centurion, 1990.

COSTA, Jurandir F. Violência e psicanálise. 2. ed. Rio de Janeiro: Ed. Graal, 1986.

DALAI LAMA, Décimo Quarto. Conselhos do coração. 2. ed. Rio de Janeiro: Bertrand Brasil, 2003. - A força do budismo. 5. ed. São Paulo: Mandarin, 2001.

DUMONT, Louis. O individualismo - uma perspectiva antropológica da ideologia moderna. Rio de Janeiro: Rocco, 1985.

FOUCAULT, Michel. Dits et écrits. Paris: Éditions Gallimard, 1994. Vol. I, II, III e IV.

GONÇALVES, José Artur. O budismo no oeste paulis ta: imigração, desenraizamento e ocidentalização. In: USARSKI, Frank (org.). O budismo no Brasil. São Paulo: Lorosae, 2002.

JULLIARD, André. Ethnologie des religions: um état de crise ? Elements de réflexion. In: LIOGER, Richard (org.). Une antropologie religieuse em Lorraine. Metz: Éditions Serpenoise, 2000.

KÖNIG, Franz e WALDENFELS, Hans. Léxico das religiōes. Petrópolis: Vozes, 1998.

LASCH, Christopher. O minimo eu. São Paulo: Brasiliense, 1986. A cultura do narcisismo. Rio de Janeiro: Imago, 1983. 
LOBATO, Eliane. Um budismo de resultados. <http:// fmspsi.sites.uol.com.br/brhbuda.htm>. Acesso em 12/10/2003.

LUCKMANN, Thomas. La religión invisible: el problema de la religión en la sociedad moderna. Salamanca: Ediciones Sígueme, 1973.

MATSUE, Regina. O budismo na Terra Pura em Brasília. In: USARSKI, Frank (org.). O budismo no Brasil. São Paulo: Lorosae, 2002.

MONTES, Maria Lúcia. As figuras do sagrado: entre o público e o privado. In: História da vida privada no Brasil: contrastesda intimidade contemporânea. São Paulo: Companhia das Letras, 1998, vol. 4.

SANTOS, Lyndon. Resenha sobre O budismo no Brasil, de Frank Usarski. $<$ http://www.pucsp.br/rever/resenha.htm>. Acesso em 10/10/2003.

SHOJI, Rafael. Uma perspectiva analítica para os convertidos ao budismo japonês no Brasil. In: Rever: Facetas da Conversão Religiosa. São Paulo: PUCSP, 2002, ano 2, n. 2.

TROELTSCH, Ernst. Histoire des religions et destin de la théologie. Paris: Les Éditions du Cerf, 1996.

TAYLOR, Charles. As fontes do self: a construção da identidade moderna. São Paulo: Edições Loyola, 1997.

USARSKI, Frank. O budismo no Brasil: um resumo sistemático.In: (org.). O budismo no Brasil. São Paulo: Lorosae, 2002.

VERNETTE, Jean e MONCELON, Claire. Dictionnaire des groupes religieux aujourd'hui. Paris: Presses Universitaires de France, 2001. 